\title{
In vivo and in vitro investigations of a nanostructured coating material - a preclinical study
}

This article was published in the following Dove Press journal:

International Journal of Nanomedicine

14 February 2014

Number of times this article has been viewed

\author{
Martin Adam' \\ Cornelia Ganz' \\ Weiguo $\mathrm{Xu}{ }^{\prime}$ \\ Hamid-Reza Sarajian ${ }^{2}$ \\ Werner Götz ${ }^{3}$ \\ Thomas Gerber' \\ 'Institute of Physics, Rostock \\ University, Rostock, Germany; \\ ${ }^{2}$ Department of Oral and Maxillofacial \\ Plastic Surgery, Rostock University, \\ Rostock, Germany; ${ }^{3}$ Department \\ of Orthodontics, Center of Dento- \\ Maxillo-Facial Medicine, Faculty of \\ Medicine, University of Bonn, Bonn, \\ Germany
}

Correspondence: Thomas Gerber Universitätsplatz 3, Institute of Physics, Faculty of Mathematics and Natural Sciences, Rostock University,

I 8055 Rostock, Germany

Tel +493814986840

Fax +49 38I 4986862

Email thomas.gerber@uni-rostock.de
Abstract: Immediate loading of dental implants is only possible if a firm bone-implant anchorage at early stages is developed. This implies early and high bone apposition onto the implant surface. A nanostructured coating material based on an osseoinductive bone grafting is investigated in relation to the osseointegration at early stages. The goal is to transmit the structure (silica matrix with embedded hydroxyapatite) and the properties of the bone grafting into a coating material. The bone grafting substitute offers an osseoinductive potential caused by an exchange of the silica matrix in vivo accompanied by vascularization. X-ray diffraction and transmission electron microscopy analysis show that the coating material consists of a high porous silica matrix with embedded nanocrystalline hydroxyapatite with the same morphology as human hydroxyapatite. An in vitro investigation shows the early interaction between coating and human blood. Energy-dispersive X-ray analysis showed that the silica matrix was replaced by an organic matrix within a few minutes. Uncoated and coated titanium implants were inserted into the femora of New Zealand White rabbits. The bone-to-implant contact (BIC) was measured after 2,4 , and 6 weeks. The BIC of the coated implants was increased significantly at 2 and 4 weeks. After 6 weeks, the BIC was decreased to the level of the control group. A histological analysis revealed high bone apposition on the coated implant surface after 2 and 4 weeks. Osteoblastic and osteoclastic activities on the coating material indicated that the coating participates in the bone-remodeling process. The nanostructure of the coating material led to an exchange of the silica matrix by an autologous, organic matrix without delamination of the coating. This is the key issue in understanding initial bone formation on a coated surface.

Keywords: silica, hydroxyapatite, dental implants, matrix change, osseointegration, in vivo

\section{Introduction}

Dental implants are widely used for tooth replacement. Several implant designs and systems have had high clinical success rates. The conventional protocol for dental implant placement is divided into two phases. ${ }^{1,2}$ During the first, so called 'surgical phase', the implant is installed and the surgical site has to be undisturbed for 3-6 months, when the prosthesis is mounted in the second 'prosthesis phase'. This two-stage surgical protocol includes a transitional removable prosthesis with its problems and discomfort, and the physiological and psychological challenges for patients caused by the additional surgery. ${ }^{3}$ Therefore, research is focused on immediate or early implant loading after implantation. Immediate implant loading is defined as loading within 24-48 hours and early implant loading as within 14 days. ${ }^{1}$ A basic requirement for rapid loading is the stability of the implant-bone anchorage at early stages, which implies early bone apposition onto the implant surface. ${ }^{3,4}$ But the primary stability of 
conventional implant surfaces decreases during the first few weeks, and the so-called secondary stability increases only after 5-8 weeks. This effect leads to a minimum in the stability of implant fixation in the early stages. Consequently, most implant failure occurs during a period of 2-4 weeks. ${ }^{5}$

Several possibilities of enhancing the osseointegration at early stages seem possible. The role of surface roughness is manifold discussed and the benefit of rough implant surfaces in comparison to smooth or machined is shown in many studies. Rough implant surfaces induce higher bone-toimplant contact (BIC) rates and torque-removal values. ${ }^{6-9}$

Calcium phosphate layers such as hydroxyapatite (HA), tri-calcium phosphates (TCPs), and others carry further possibilities for enhancing osseointegration. It is reported that calcium phosphate (CaP)-coated implants exhibit osteoconductive behavior and offer an improvement in osseointegration. ${ }^{6,10-14}$ In addition, $\mathrm{CaP}$ coatings show a higher protein (growth factors)-binding affinity and therefore promote the differentiation of osteoblast- and osteoclast-like cells. ${ }^{4,10,12,15}$ But the resorption of $\mathrm{CaP}$ coatings strongly depends on the chemical composition and structural configuration of the material. ${ }^{15}$ The solubility can differ in two orders of magnitude depending on the chemical composition. ${ }^{16}$ Therefore, the resorption that has been reported several times is an effect of dissolution of the $\mathrm{CaP}$ layer rather than a bone remodeling. ${ }^{6,10,12,17}$ The discrepancy in dissolution between the various phases in the coating can lead to delamination and particle release, which can result in clinical problems, ending with implant failure. ${ }^{18-22}$

A third point in osseointegration is the application of osteogenic agents such as bone morphogenetic proteins (BMPs). It is possible to render implants osseoinductive. ${ }^{23-25}$ BMPs stimulate the recruitment, proliferation, and differentiation of not only osteoprogenitor cells but also of osteoclasts at an early stage. ${ }^{26}$ It has been shown that the applied dose of the drug is critical, since an overdose can trigger the production of BMP inhibitors. ${ }^{27,28}$ An overdose can even result in uncontrolled bone formation in the defect. ${ }^{29,30}$

This study aimed to enhance the osseointegration at early stages via an autologous self-coating. To this end, the use of a new nanostructured coating material is suggested. The basic concept of this coating material is the synthetic bone grafting material NanoBone ${ }^{\circledR}$ Artoss GmbH, RostockWarnemünde, Germany. It consists of a highly porous silica matrix with embedded nanocrystalline hydroxyapatite (ncHA), which has a morphology identical to that of human HA. ${ }^{31-33}$ It has been shown that the structure of the bone grafting leads to fast osteogenesis and resorption by bone remodeling. ${ }^{34-36}$ Moreover, several studies have revealed an osteoinductive behavior of this bone grafting material. It was found that the osseoinductive behavior is obtained by an exchange of the silica matrix in vivo, ie, the silica matrix is replaced by an organic matrix consisting of autologous macromolecules within a few days. The matrix change at very early stages is attended by vascularization, which ensures nutrition and metabolism of the proliferating and/or migrating cells. ${ }^{35-37}$ Silicon as a trace element plays an active role in bone mineralization and calcification, and even silicon-substituted HA resulted in faster bone remodeling. ${ }^{38-42}$

\section{Materials and methods Coating routine}

The coating was produced by a spin-and-spray coating process. The implant was fixed in a stainless steel implant holder and rotated around its longitudinal axis. Before coating, the implant surfaces were activated by atmospheric oxygen plasma (PlasmaBeam; Diener electronic $\mathrm{GmbH}$, Ebhausen, Germany) and cleaned of hydrocarbons and other carbon molecules, rendering the implant surface hydrophilic. ${ }^{43,44}$

The coating dispersion consisted of ncHA and a $\mathrm{SiO}_{2}-$ sol (silica). The dispersion medium was ethanol. The ncHA was derived by precipitation of diluted solutions of calcium chloride and sodium hydrogen phosphate at a controlled temperature and $\mathrm{pH}$ adjusted with ammonia solution. The formed HA crystals were washed with deionized water and triple rinsed with pure ethanol to diminish the amount of water. $^{33}$

The $\mathrm{SiO}_{2}$-sol was derived by hydrolysis of tetraethyl orthosilicate with an acid catalyst. The molar ratio of water to tetraethyl orthosilicate was 4.

The slurry of ncHA and the $\mathrm{SiO}_{2}$-sol was homogeneously dispersed in ethanol with a weight ratio of $\mathrm{HA}: \mathrm{SiO}_{2}$ of 76:24. After homogenization with ultrasonic treatment, the dispersion was sprayed onto the implant surfaces with a twosubstance nozzle (970; Düsen-Schlick GmbH, Untersiemau/ Coburg, Germany).

During the drying routine (dry and oil-free air flow, Carat 106/E, FIAC, Bologna, Italy), the ethanol evaporated and the silica sol formed a three-dimensional network with embedded HA crystals. Subsequently, the residual ethanol groups in the silica gel were removed by further atmospheric plasma treatment.

The whole coating routine was embedded in a laminar flow box (Herasafe HSP12, class 2; Heraeus, Hanau, 
Germany) and controlled by computer software to guarantee reproducibility.

All chemical reagents were specified as Reagent European Pharmacopoeia Grade and obtained from Sigma-Aldrich, St Louis, MO, USA.

\section{Coating characterization}

For scanning electron micrographs (SEM) (DSM960; Zeiss, Oberkochen, Germany), coated and uncoated implants were sputtered with an $\mathrm{Au} / \mathrm{Pd}$ layer (thickness about $5 \mathrm{~nm}$ ). Images were taken at different magnifications with an acceleration voltage of $10 \mathrm{kV}$. For calculation of a three-dimensional surface model, tilted images were collected at three different angles (Stereo-SEM, MeX5.1; Alicona Imaging GmbH, Graz, Austria). The magnification was adjusted in that way to eliminate screw threads. The mean roughness $\left(\mathrm{s}_{\mathrm{A}}\right)$ of the implant surface was calculated from the surface model by area analysis using a Gaussian filter with cut-off wavelength of $500 \mu \mathrm{m}$.

The local chemical composition was determined by energy-dispersive X-ray analysis (EDX) using SEM equipped with a $\mathrm{Si}(\mathrm{Li})$ detector (SAMx, Saint Laurent Du Var, France) using an acceleration energy of $10 \mathrm{keV}$.

The nanostructure of the coating material was investigated by transmission electron microscopy (TEM) and scanning TEM (STEM) (TEM/STEM EM912, Zeiss, Oberkochen, Germany), operated at $100 \mathrm{kV}$. Copper grids with a carbonhole film were used as sample holder. Micrographs were taken in conventional transmission mode and scanning transmission mode (STEM) using a secondary electron (SE) detector.

$\mathrm{X}$-ray powder diffraction (XRD) of the ncHA and human HA was conducted in reflection with a position sensitive detector (Inel Inc, Stratham, NH, USA) and $\mathrm{Cu}$ $\mathrm{K} \alpha$ radiation.

For determination of the tensile bond strength, four Ti6Al4V test rods (Zwick Roell Z050-50 kN; Ulm, Germany) with a sand-blasted surface were coated as described above. The coated rods were fixed to another identical rod by heatcured epoxy according to the standard test method for adhesion or cohesion strength of thermal spray coatings (ASTM C633). The two fixed rods were pulled in tension using an all-round testing machine (Zwick Roell). The force was measured until failure occurred. The tensile strength is calculated by dividing the force by the cross-sectional area.

\section{In vitro}

To analyze if the matrix change occurs within the coating material, the interaction of the coating with human blood was investigated. Coated implants were kept in $3 \mathrm{~mL}$ of human blood. No coagulation inhibitors, such as heparin, were used. The temperature was adjusted to approximately $36^{\circ} \mathrm{C}-37^{\circ} \mathrm{C}$ to keep the thermodynamics constant. Specimens were removed after $0.5,1,3$, and 5 hours and fixed with $4 \%$ formaldehyde solution. The coagulated blood was removed mechanically and, after critical point drying, the silicon concentration was determined by EDX analysis at different positions. Furthermore, histological cross sections according to the sawing and grinding technique were prepared and stained with toluidine blue. ${ }^{45}$

\section{In vivo New Zealand White rabbits}

Commercial sand-blasted titanium implants (diameter $=$ $3.7 \mathrm{~mm}$, length $=9.0 \mathrm{~mm}$, tioLogic ${ }^{\odot}$; Dentaurum $\mathrm{GmbH}$ and $\mathrm{Co}, \mathrm{KG}$, Germany) were used. The coated implants were produced as described above. Coated (NanoBone ${ }^{\circledR}$ coating: NB-C) and uncoated (control) implants were sterilized using heat for 4 hours at $160^{\circ} \mathrm{C}$.

All animal handling and surgical procedures were conducted according to European Community guidelines for the care and use of laboratory animals (DE 86/609/ $\mathrm{CEE}$ ) and approved by the local veterinary school ethical committee.

All implants ( $\mathrm{n}=6$ per time, per implant group) were inserted under general anesthesia (10\% ketamine [bela-pharm, Germany], 2\% xylazine [Rompun ${ }^{\circledR}$ Bayer AG, Leverkusen, Germany] and, after 10 minutes, $0.3 \mathrm{~mL}$ atropin $[0.5 \mathrm{mg} / \mathrm{mL}$; Ratiopharm GmbH, Ulm, Germany]) in the femora of New Zealand White rabbits (Charles River Laboratories, Sulzfeld, Germany). Additionally, as analgesic and antibiotic, metamizole sodium (500 mg/mL, Novaminsulfon; Ratiopharm $\mathrm{GmbH}$ ) and penicillin G (IM 150,000 IE) were injected. Local anesthesia was carried out with $2 \mathrm{~mL}$ xylocitin-Ioc $(2 \% / \mathrm{mL})$ and the wound was washed with gentamicin $(80 \mathrm{mg} / 2 \mathrm{~mL} ; 1: 5$ dilution with $\mathrm{NaCl}$ ) after implant insertion. Novaminsulfon was added to the drinking water for 3 days.

The animals were euthanized with pentobarbital (Release $^{\circledR}$; Richter Pharma, Wels, Austria) after 2, 4, and 6 weeks, and the specimens were excised. The implants were processed for histological preparation of undecalcified sections according to the sawing and grinding technique. Polished sections were prepared parallel to the longitudinal implant axis and stained with toluidine blue. ${ }^{45}$

To determine the osseointegration, the BIC was measured. The BIC is the ratio of the sum of the direct bone-implant bonding and the circumference of the implant surface in two dimensions. 
From the polished sections, the complete implant boundary was photographed by light microscopy (original magnification 50-fold). All images were combined as one image with a resolution of $1.3 \mu \mathrm{m}$ per pixel. This guarantees a measurement at a high magnification of the BIC and allows explicit identification of bone or connective tissue.

The BIC was measured by semi-automatic software (Axiovision 4.8; Zeiss, Germany). The length of the implant circumference was measured automatically. The direct contact of bone to the implant contour was marked manually.

\section{Statistical analysis}

One-way analysis of variance (ANOVA; Microcal Origin 5.0, Northampton, MA, USA) was conducted to determine the significance of the BIC values of the implant groups. The mean values and the standard deviation of the mean were calculated. A $P$-value of 0.05 was considered statistically significant.

To analyze the silica concentration (derived from EDX) at the blood treatment, the means and the standard deviations of the means were calculated (Microsoft ${ }^{\circledR}$ Excel, Redmond, WA, USA).

\section{Results}

\section{Coating characterization}

In Figure 1A, the surface topography of the sand-blasted titanium implants is shown in a Stereo-SEM image. The rough surface is characterized by statistically distributed furrows in the range of 10-100 $\mu \mathrm{m}$ due to the sand-blasting particles used. The calculated mean surface roughness was $4.7 \mu \mathrm{m}$. Figure 1B is a Stereo-SEM of the NB-C surface. The calculated mean surface roughness has decreased to $2 \mu \mathrm{m}$.

Figure $2 \mathrm{~A}$ and $\mathrm{B}$ show the microstructure of the coating on the implant surface well. In Figure 2A, the homogeneous coverage of the coarse thread with NB-C is apparent. The thickness of the coating is $10 \mu \mathrm{m}$. The morphology of the coating material is shown at a higher magnification in Figure 2B.
The material offers pores and holes in the lower micrometer and nanometer scale, which generate a high surface.

Figure 3 shows a TEM micrograph of the ncHA as one component of the coating dispersion. The HA consists of thin platelets with the following physical dimensions: length 50-70 nm; width 20-25 nm; and thickness 3-4 nm. The thickness of the crystals is observable as dark acicular lines when they are orientated parallel to the incident electron beam. In Figure 4, the XRD pattern of the ncHA is compared with that of human bone. All peaks of the ncHA pattern belong to the crystalline phase HA. Both patterns offer broadened peaks at the same positions and with the same peak ratios. That means the synthetic ncHA has an identical morphology to human HA.

The nanostructure of the coating material is shown in Figure 5. The TEM micrograph (Figure 5A) shows the silica gel with the embedded HA crystals. The silica gel is a xerogel network and is visible as very small granular structures, about 0.5-1 nm, on and between the HA crystals. For a higher magnification, see Figure 5B. In comparison with the TEM of the pure ncHA (Figure 3), where the HA crystals are loosely packed, the HA crystals in the coating are fully surrounded by the $\mathrm{SiO}_{2}$ gel. The coating material shows interconnected pores in the nanometer scale. Figure $5 \mathrm{C}$ is an SEM picture derived from the STEM mode using an SE detector. This is sensitive for the surface of the specimen and gives an image of the surface topography. The coating is characterized by a rough surface with many nanopores due to the morphology of the HA crystals and the silica matrix.

The tensile bond test with the coated test rods revealed a tensile bond strength of $45.0 \pm 1.5 \mathrm{MPa}$, which is above the minimum tensile bond strength of $22 \mathrm{MPa}$ for plasma-sprayed coatings defined by the US Food and Drug Administration (FDA). ${ }^{46}$

\section{In vitro}

A histological cross section of the coating after blood treatment for 30 minutes is shown in Figure 6A. The coating still
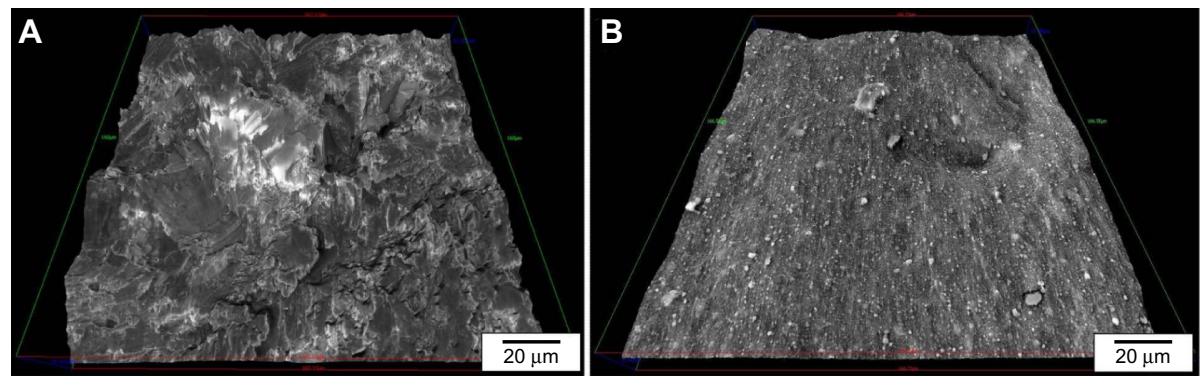

Figure I 3D-Stereo SEM of the implant surface without $(\mathbf{A})$ and with coating (B).

Abbreviations: NB-C, NanoBone ${ }^{\circledR}$ (Artoss GmbH, Rostock-Warnemünde, Germany) coated group; SEM, scanning electron micrograph. 

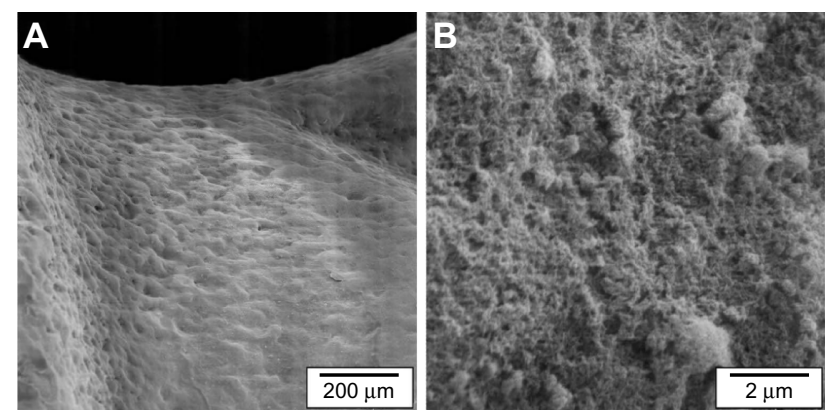

Figure 2 SEM images of the coating microstructure on the screw thread (A) and at a higher magnification (B). The coating topography exhibits a high porosity and high surface.

Abbreviations: NB-C, NanoBone ${ }^{\circledast}$ (Artoss GmbH, Rostock-Warnemünde, Germany) coated group; SEM, scanning electron micrographs.

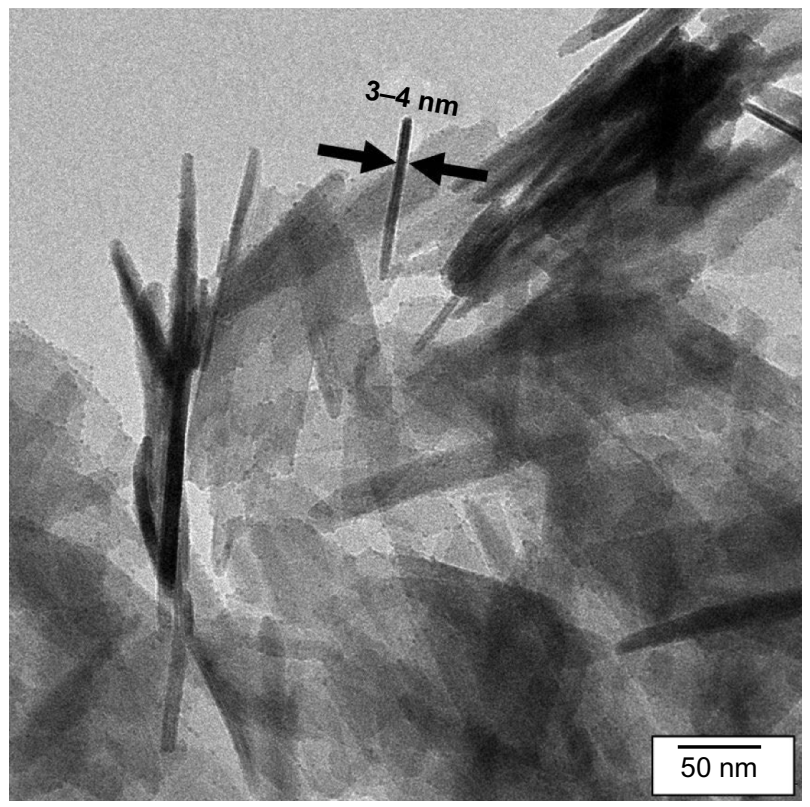

Figure 3 TEM of the nano-crystalline hydroxyapatite (ncHA). The ncHA consists of thin platelets (length: $50-70 \mathrm{~nm}$, width: $20-25 \mathrm{~nm}$, thickness: $3-4 \mathrm{~nm}$, see arrows). The thickness is visible as needle-like structures when the platelets are oriented parallel to the electron beam.

Abbreviation: TEM, transmission electron microscopy.

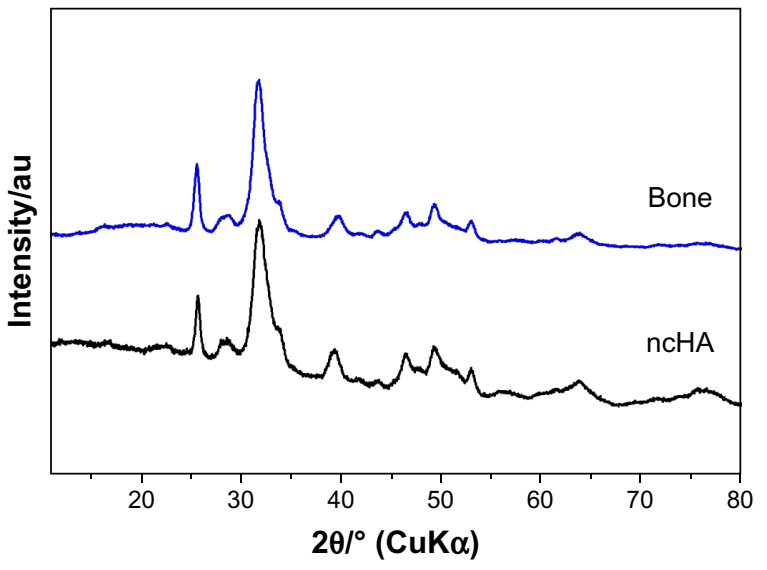

Figure 4 XRD patterns of human bone (bone) and the nano-crystalline hydroxyapatite. The ncHA has the same morphology as natural apatite; see peak positions, ratios and widths.

Abbreviations: ncHA, nanocrystalline hydroxyapatite; $\mathrm{XRD}, \mathrm{X}$-ray powder diffraction. exists and did not dissolve. It is visible as light bands (arrows) on the implant surface. The silicon concentration (in at \%, as a part of silica) of the coating after blood treatment was determined by EDX analysis and is shown in Figure 6B. The results are normalized to the default silicon concentration before blood treatment. After blood treatment for 30 minutes, the silicon amount is only $20 \%$ of the original concentration. This value is stable over the whole period of 5 hours. The pretended minimum at 1 hour is not real and is in the magnitude of error. The replacement of the silica matrix by an organic matrix occurred within 30 minutes and achieves saturation, due to the blood volume of $3 \mathrm{~mL}$. The exchange of the silica matrix is much faster in comparison with the grafting material (10 days).

\section{Histomorphometric analysis in rabbits}

The results of the BIC measurement are illustrated in Figure 7. The BIC of the control group increased within 6 weeks from $42 \%$ after 2 weeks up to $50 \%$ after 6 weeks. The BIC of the coated implants (NB-C) is significantly higher than that of the control group after $2(66 \%)$ and 4 weeks $(65 \%)(P<0.005)$. After 6 weeks, the BIC of NB-C has decreased to the level of the control group. The difference after 6 weeks between the control group and NB-C is not significant. The initial enhanced BIC after the first 4 weeks is smoothed out after 6 weeks.

\section{Histological analysis in rabbits}

No animals showed abnormal behavior after implantation. After 2 and 4 weeks, both groups, control and coated implants (Figure 8A-D), showed the formation of cancellous periimplant bone with intertrabecular loose connective tissue, vessels, and fatty bone marrow and focally osteoblast seams, ie, a good peri-implantosteogenesis. Remarkably, most of the surface of the coated group (NB-C, Figure 8B) was covered by bone (white arrows). Conversely, the control group (Figure 8A) showed less bone contact. The same behavior was found after 4 weeks for both, respectively. After 6 weeks (Figure $8 \mathrm{E}$ and $\mathrm{F}$ ), both groups showed matured bone. Conspicuously, the bone attachment of the coated group (NB-C) is diminished in comparison with 2 and 4 weeks (Figure 8B and D). In accordance to the histomorphometric data, no difference between the uncoated and coated group remains after 6 weeks.

In higher magnification, after 2 weeks (Figure 9A and B) both groups showed blood vessels, bone marrow, high osteoblastic activity, and newly formed bone. For the control group, bone formation occurred in the direction of the implant surface. In 

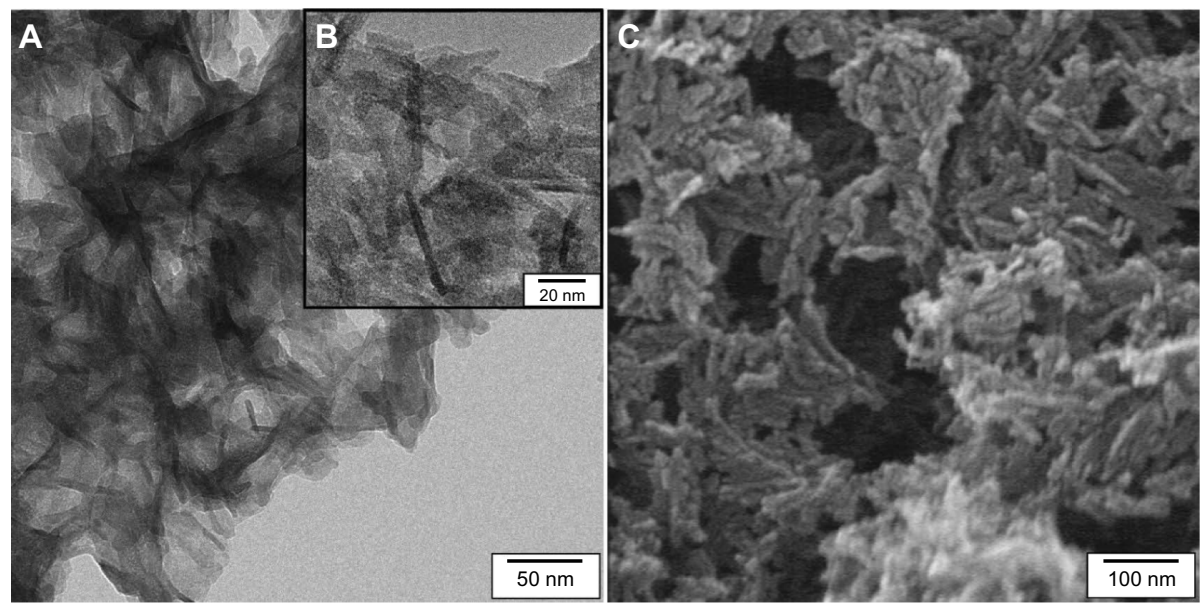

Figure 5 TEM image (A) of the coating with its ncHA embedded in the silica matrix. The silica matrix is a xerogel network and encloses the HA-crystals (B). SEM image of the coated surface $(\mathbf{C})$ shows the porosity in the nanometer scale.

Abbreviations: TEM, transmission electron microscopy; SEM, scanning electron micrographs; ncHA, nanocrystalline hydroxyapatite; HA, hydroxyapatite.

many cases, there is still connective tissue between newly formed bone and the implant surface, see Figure 9A (white arrow).

On the other hand, in the NB-C group, bone formation occurred directly on the implant surface. In Figure 9B, an osteoblastic border is forming osteoid on the coating interface (black arrows). Osteocytes are included in the newly formed bone on the coating material (asterisks). A tight compound of new bone and coating is developed. After 4 weeks (Figure 9D), osteoblastic seams are also present. The bone, which is formed on the coating surface, has matured into lamellar bone, ie, more osteocytes have differentiated and the former osteoid is mineralized.

Generally, after 6 weeks (Figure 9E and F), the bone in both groups was matured. The control group showed no significant differences to 2 and 4 weeks (Figure 9A and C).

In comparison with 2 and 4 weeks, the peri-implant region of the coated surface (Figure 9F) showed resorption lacunae of osteoclasts (black arrows), which explains the reduction of the BIC after 6 weeks. The initial bone attachment was removed by bone remodeling processes.

\section{Discussion}

One goal of the study was to develop a nanostructured, osseoinductive coating on implants. The micro- and nanometer structure of the coating were presented. The tensile bond strength was higher than the required minimum for HA coatings on metal implants. ${ }^{46}$ SEM investigations revealed a homogeneous coverage with a thickness of about $10 \mu \mathrm{m}$. The coating reduced the roughness of the implant surface to $2 \mu \mathrm{m}$. But the described coating material is remodeled by osteogenic processes (Figure 9, discussed later) and therefore, the original implant surface roughness plays a crucial role at a later date. ${ }^{9}$

From XRD analysis, the identical morphology between the synthetic hydroxyapatite (ncHA) and bone was apparent. The peak broadening of both samples indicated the same

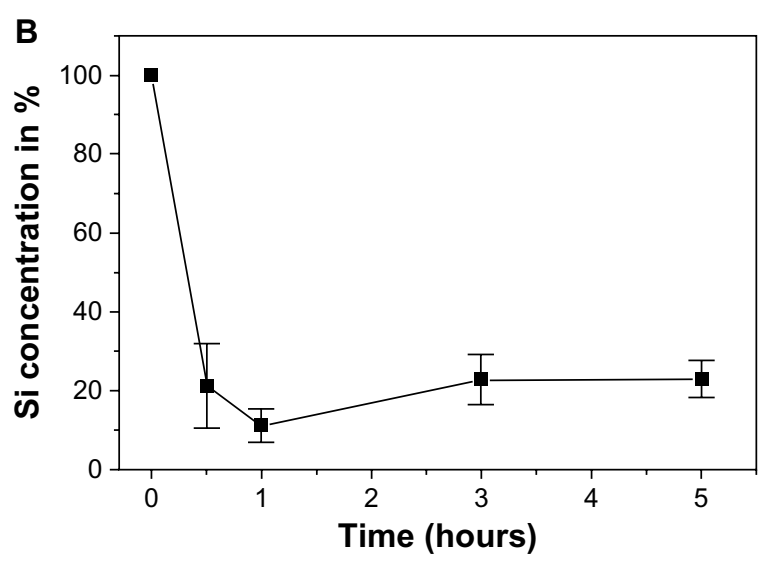

Figure 6 Histological cross section after blood treatment for 30 minutes (A). The coating did not dissolve (arrows), but the silica concentration decreased within 30 minutes (B). 


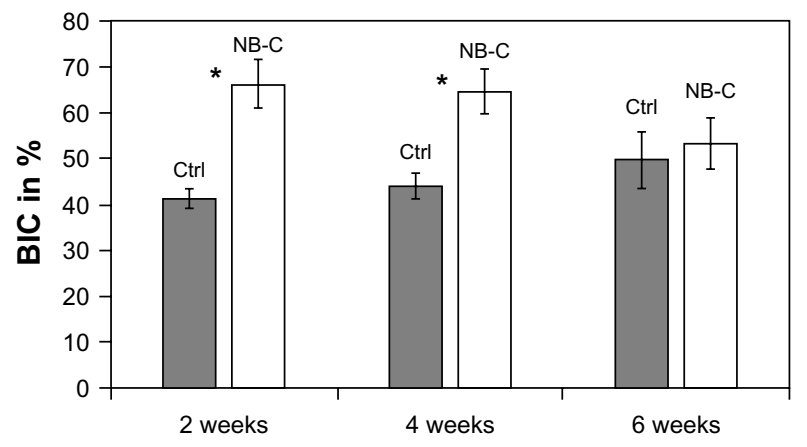

Figure 7 Bone-to-implant-contact of the control and coated group. The BIC of the coated group is enhanced considerably against the control group after 2 and 4 weeks. After 6 weeks the difference is not significant; for explanation see text. Note: $* P<0.005$.

Abbreviations: BIC, bone-to-implant contact; Ctrl, control group; NB-C, NanoBone ${ }^{\circledR}$ (Artoss $\mathrm{GmbH}$, Rostock-Warnemünde, Germany) coated group.

crystal morphology. In addition, the TEM micrograph of the ncHA (Figure 3) confirmed this. TEM and STEM investigation demonstrated (Figure 5) that these ncHA platelets were fully embedded in the silica matrix. This silica matrix, which was derived via a sol-gel process, is a porous matrix itself. It is characterized by numerous open bonds ( $\mathrm{Si}-\mathrm{OH}$ or $\mathrm{Si}^{-} \mathrm{O}^{-}$, depending on the $\mathrm{pH}) .{ }^{47-50}$ The composite of ncHA and $\mathrm{SiO}_{2}$ has a high number of interconnected pores in the nanometer scale and therefore a high inner surface (Figure 5). Xu et al found an inner surface of about $168 \mathrm{~m}^{2} / \mathrm{g}$ for injectable
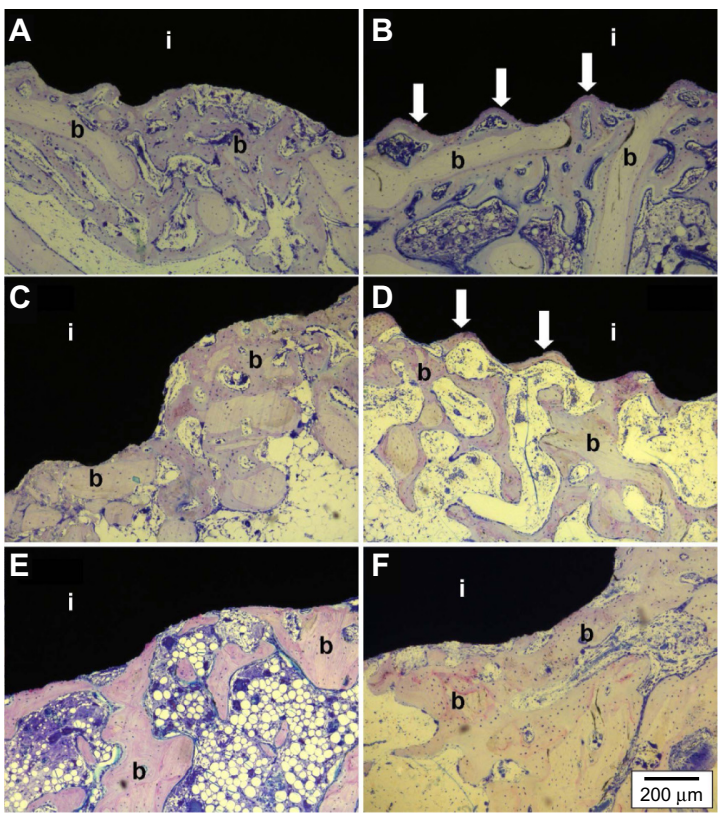

Figure 8 Histological cross sections after 2, 4 and 6 weeks of the control group (A: 2 weeks, C: 4 weeks, E: 6 weeks) and the coated group (B: 2 weeks, D: 4 weeks, F: 6 weeks). Both groups showed a good periimplantosteogenesis, ie, formation of cancellous periimplant bone, intratrabecular loose connective tissue, vessels and fatty bone marrow. Moreover the coated group showed bone formation directly on the implant surface (white arrows).

Abbreviations: i, implant; b, bone.
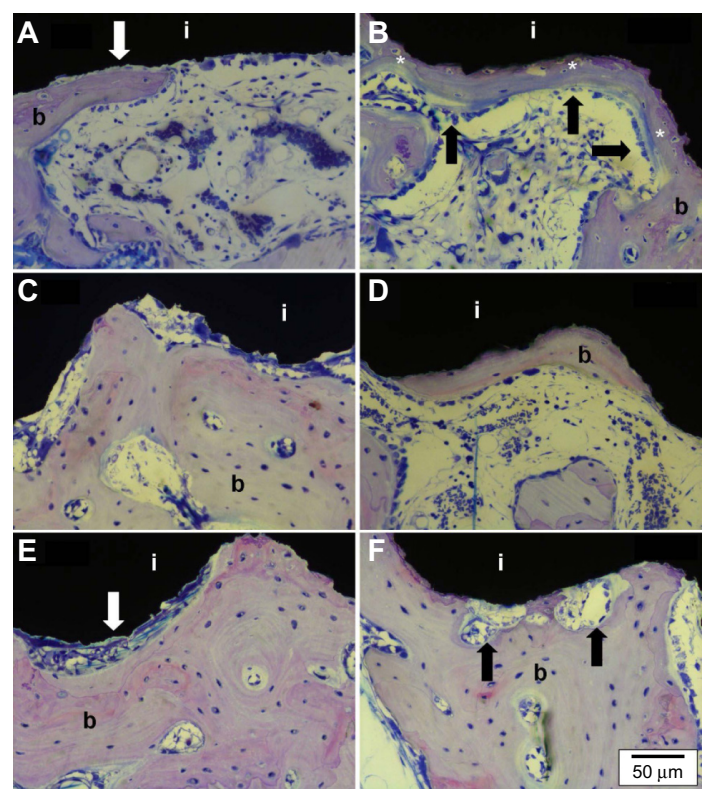

Figure 9 Higher magnification of the histological cross sections after 2, 4 and 6 weeks of the control group (A: 2 weeks, C: 4 weeks, E: 6 weeks) and the coated group (B: 2 weeks, D: 4 weeks, F: 6 weeks). Osteoblastic seams (B, black arrows) formed osteoid (asterisk) onto the coating. The decreased BIC after 6 weeks (Figure 7 ) is caused by osteoclastic resorption ( $\mathbf{F}$, black arrows), ie bone remodeling. Abbreviations: BIC, bone-to-implant contact; i, implant; b, bone.

silica-embedded nanohydroxyapatite microspheres, which were structurally equal to the coating. ${ }^{33}$ The high inner surface and the negative surface charge offered the possibility of high protein adsorption..$^{35,51}$

In comparison with the findings of the bone substitute concerning matrix change, the interaction of the coating material with human blood was analyzed. Since the structure of the bone grafting and the coating material is similar, the obtained results are conferrable. EDX analyses revealed that the silica amount is reduced to $20 \%$ of the original composition within 30 minutes, although the solubility of silica is in the range of $100 \mathrm{ppm}$ at a physiologic $\mathrm{pH}$ of $7.4 .^{50,52}$ Other studies investigating the use of silica xerogel for drug delivery reported that silica xerogels exhibited a weight loss of about $30 \%$ after several days in simulated body fluid. ${ }^{53-55}$ In our study, the loss was $80 \%$ after 30 minutes - in comparison, a very fast exchange. Assuming that the silica matrix would be dissolved and not exchanged, the residual HA crystals would delaminate. But the coating was still present on the implant surface (Figure 6A). The reported matrix change in this study is not explained by dissolution - it seems to be a kind of substitution reaction, which can not be specified at this point. The leading part in that context is the protein affinity of the HA crystals and therefore the (specific) protein adsorption. It is known that calcium phosphates, eg, HA, exhibit a high affinity for protein adsorption. ${ }^{56-58}$ Götz et al have found that 
bone-specific proteins, such as BMP-2, osteocalcin, osteopontin, etc, were adsorbed by the bone-grafting substitute, which is structurally identical to the described coating material. Furthermore, it is reported that a proteinaceous matrix was formed. ${ }^{35,36}$ From this point, we can only assume a similar behavior, but the comparable findings in SEM and EDX investigations confirm our suggestions. Since the ncHA is embedded in the silica matrix with high specific surface area, the replacement of the silica by proteins may lead to a high protein/HA ratio, which promotes the osseointegration.

The in vivo investigation with New Zealand White rabbits is consistent with the findings given above. It showed an enhanced BIC within the first 4 weeks. The histological analysis revealed a directed bone formation that is induced by the coating. New bone is priorly formed directly at the coated implant surface. High osteoblastic activity and osteoblastic seams on the coating confirm that point. After 6 weeks, the initial bone formation decreases as a result of osteoclastic resorption. The BIC decreases to the magnitude of that of the control group. An explanation for this is the faster bone metabolism of rabbits compared with humans, ie, 6 weeks in vivo can not be considered as early stage. ${ }^{59}$ Of course, no implant loading occurred during that time period. Accordingly, no mechanical stress was induced into the peri-implant region. Probably, in combination with the faster bone metabolism of rabbits, the initial bone formation was diminished.

The matrix change is understood to be the key issue of the osteoinductive behavior of the bone grafting material. ${ }^{35,37}$ Therefore, the early bone formation on the coating material is associated with the exchange of the silica matrix by autologous molecules. The osteoblastic seams on the coating are an indication to confirm this point. Although it is still a matter of debate how materials induce the very first stages of osteogenesis, ${ }^{60}$ the adsorption of specific proteins and integrins is generally seen as important. To understand the effect of the initial bone formation at these very early stages, it is necessary to investigate which proteins adsorb on the coating material within these time scales.

\section{Conclusion}

The investigated coating material consists of a highly porous silica matrix with embedded ncHA, which is morphologically identical to human HA. This compound, silica matrix and HA, induces an initial matrix change shortly after implantation. The silica matrix is replaced by an organic matrix - a kind of self-coating procedure with autologous proteins and molecules. The coating material changes its composition. Therefore, the original coating material has to be considered as a temporary coating. This newly in vivo-formed material leads to a considerably enhanced BIC and induces bone formation directly on the implant surface.

\section{Acknowledgments}

The authors would like to thank D Gütschow for technical assistance and Dentaurum $\mathrm{GmbH}+\mathrm{Co}, \mathrm{KG}$ for the supply of the implants. The research was funded by the Federal State Government of Mecklenburg-Vorpommern, Germany.

\section{Disclosure}

The authors report no conflicts of interest in this work.

\section{References}

1. Elias CN, Meirelles L. Improving osseointegration of dental implants. Expert Rev Med Devices. 2010;7:241-256.

2. Laney WR, Tolma DE, Keller EE, Desjardins RP, Van Roekel NP, Brånemark PI. Dental implants: tissue-integrated prosthesis utilizing the osseointegration concept. Mayo Clin Proc. 1986;61:91-97.

3. Gapski R, Wang HL, Mascarenhas P, Lang NP. Critical review of immediate implant loading. Clin Oral Implants Res. 2003;14(5):515-527.

4. LeGuéhennec L, Soueidan A, Layrolle P, Amouriq Y. Surface treatments of titanium dental implants for rapid osseointegration. Dent Mater. 2007;23:844-854.

5. Raghavendra S, Wood MC, Taylor TD. Early wound healing adjacent to endosseous dental implants: a review of the literature. Int J Oral Maxillofac Implants. 2005;20(3):425-431.

6. Buser D, Schenk RK, Steinemann S, Fiorellini JP, Fox CH, Stich H. Influence of surface characteristics on bone integration of titanium implants. A histomorphometric study in miniature pigs. J Biomed Mater Res. 1991;25(7):889-902.

7. Rønold HJ, Lyngstadaas SP, Ellingsen JE. A study on the effect of dual blasting with $\mathrm{TiO}_{2}$ on titanium implant surfaces on functional attachment in bone. J Biomed Mater Res A. 2003;67:524-530.

8. Wennerberg A, Ektessabi A, Albrektsson T, Johansson C, Andersson B. A 1-year follow-up of implants of differing surface roughness placed in rabbit bone. Int J Oral Maxillofac Implants. 1997;12:486-494.

9. LeGuehennec L, Goyenvalle E, Lopez-Heredia MA, Weiss P, Amouriq Y, Layrolle P. Histomorphometric analysis of the osseointegration of four different implant surfaces in the femoral epiphyses of rabbits. Clin Oral Impl Res. 2008;19:1103-1110.

10. Darimont GL, Cloots R, Heinen E, Seidel L, Legrand R. In vivo behaviour of hydroxyapatite coatings on titanium implants: a quantitative study in the rabbit. Biomaterials. 2002;23:2569-2575.

11. Junker R, Manders PJ, Wolke J, Borisov Y, Jansen JA. Bone-supportive behaviour of microplasma-sprayed cap-coated implants: mechanical and histological outcome in the goat. Clin Oral Implants Res. 2009;21:189-200

12. Sun L, Berndt CC, Gross KA, Kucuk A. Material fundamentals and clinical performance of plasma-sprayed hydroxyapatite coatings: a review. J Biomed Mater Res. 2001;58:570-592.

13. Aebli N, Krebs J, Stich H, et al. In vivo comparison of the osseointegration of vacuum plasma sprayed titanium- and hydroxyapatite-coated implants. J Biomed Mater Res A. 2003;66:356-363.

14. Maxian SH, Zawadsky JP, Dunn MG. Mechanical and histological evaluation of amorphous calcium phosphate and poorly crystallized hydroxyapatite coatings on titanium implants. J Biomed Mater Res. 1993;27(6):717-728. 
15. Yang Y, Kim KH, Ong JL. A review on calcium phosphate coatings produced using a sputtering process - an alternative to plasma spraying. Biomaterials. 2005;26(3):327-337.

16. Hench LL, Wilson J, editors. An Introduction to Bioceramics. 1st ed. Singapore: World Scientific Publishing Co, Pte Ltd; 1993.

17. Clèries L, Fernández-Pradas JM, Morenza JL. Bone growth on and resorption of calcium phosphate coatings obtained by pulsed laser deposition. J Biomed Mater Res. 2000;49(1):43-52.

18. Wheeler SL. Eight-year clinical retrospective study of titanium plasmasprayed and hydroxyapatite-coated cylinder implants. Int J Oral Maxillofac Implants. 1996;11:340-350.

19. Clèries L, Martinez E, Fernández-Pradas JM, Sardin G, Esteve J, Morenza JL. Mechanical properties of calcium phosphate coatings deposited by laser ablation. Biomaterials. 2000;21(9):967-971.

20. Morscher EW, Hefti A, Aebi U. Severe osteolysis after third-body wear due to hydroxyapatite particles from acetabular cup coating. $J$ Bone Joint Surg Br. 1998;80(2):267-272.

21. Coathup MJ, Blunn GW, Flynn N, Williams C, Thomas NP. A comparison of bone remodelling around hydroxyapatite-coated, porous-coated and grit-blasted hip replacements retrieved at post-mortem. J Bone Joint Surg Br. 2001;83(1):118-123.

22. Tinsley D, Watson CJ, Russell JL. A comparison of hydroxylapatite coated implant retained fixed and removable mandibular prostheses over 4 to 6 years. Clin Oral Impl Res. 2001;12(2):159-166.

23. Liu Y, Enggist L, Kuffer AF, Buser D, Hunziker EB. The influence of BMP-2 and its mode of delivery on the osteoconductivity of implant surfaces during the early phase of osseointegration. Biomaterials. 2007;28:2677-2686.

24. Liu Y, Huse RO, de Groot K, Buser D, Hunziker EB. Delivery mode and efficacy of BMP-2 in association with implants. J Dent Res, 2007;86:84-89.

25. Hunziker EB, Enggist L, Küffer A, Buser D, Liu Y. Osseointegration: The slow delivery of BMP-2 enhances osteoinductivity. Bone. 2012; 51(1):98-106.

26. Chen D, Zhao M, Mundy GR. Bone morphogenetic proteins. Growth Factors. 2004;22(4):233-241.

27. Rosen V. BMP and BMP inhibitors in bone. Ann N Y Acad Sci. 2006; 1068:19-25.

28. Aebli N, Stich H, Schawalder P, Theis JC, Krebs J. Effects of bone morphogenetic protein-2 and hyaluronic acid on the osseointegration of hydroxyapatite-coated implants: an experimental study in sheep. J Biomed Mater Res A. 2005;73(3):295-302.

29. Poynton AR, Lane JM. Safety profile for the clinical use of bone morphogenetic proteins in the spine. Spine (Phila Pa 1976). 2002; 27(16 Suppl 1):S40-S48.

30. Perri B, Cooper M, Lauryssen C, Anand N. Adverse swelling associated with use of rh-BMP-2 in anterior cervical discectomy and fusion: a case study. Spine J. 2007;7(2):235-239.

31. Gerber T, Lenz S. Holzhüter G, et al. Nanostructured bone grafting substitutes - a pathway to osteoinductivity. Key Eng Mater. 2011; 493-494:147-152.

32. Ganz C, Xu W, Holzhüter G, Götz W, Vollmar B, Gerber T. Comparison of bone substitutes in a tibia defect model in Wistar-rats. Key Eng Mat. 2011;493-494:732-738

33. Xu W, Ganz C, Weber U, et al. Evaluation of injectable silica-embedded nanohydroxyapatite bone substitute in rat tibia defect model. Int $J$ Nanomedicine. 2011;6:1543-1552.

34. Henkel KO, Bienengräber V, Lenz S, Gerber T. Comparison of a new kind of calcium phosphate formula versus conventional calciumphosphate matrices in treating bone defects - a long-term investigation in pigs. Key Eng Mater. 2005;284-286:885-888.

35. Götz W, Gerber T, Michel B, Lossdörfer S, Henkel KO, Heinemann F. Immunohistochemical characterization of nanocrystalline hydroxyapatite silica gel (Nanobone ${ }^{\circledR}$ ) osteogenesis: a study on biopsies from human jaws. Clin Oral Impl Res. 2008;19: 1016-1026.
36. Götz W, Lenz S, Reichert C, et al. A preliminary study in osteoinduction by a nano-crystalline hydroxyapatite in the mini pig. Folia Histochem Cytobiol. 2010;48(4):589-596.

37. Xu W, Holzhüter G, Sorg H, et al. Early matrix change of a nanostructured bone grafting substitute in the rat. J Biomed Mater Res B Appl Biomater. 2009;91(2):692-699.

38. Jugdaohsingh R. Silicon and bone health. JNutr Health Aging. 2007;11: 99-110.

39. Carlisle EM. Silicon: a possible factor in bone calcification. Science. 1970;167:279-280.

40. Schwarz K, Milne DB. Growth-promoting effects of silicon in rats. Nature. 1972;239:333-334.

41. Jones LHP, Handreck KA. The relation between the silica content of the diet and the excretion of silica by sheep. J Agric Sci. 1965;65: $129-134$.

42. Sripanyakorn S, Jugdaohsingh R, Thompson RPH, Powell JJ. Dietary silicon and bone health. Nutr Bull. 2005;30:222-230.

43. Adam M, Ganz C, Xu W, Sarajian HR, Frerich B, Gerber T. How to enhance osseointegration - roughness, hydrophilicity or bioactive coating? Key Eng Mater. 2011;493-494:467-472.

44. Keuer H, Ganz C, Xu W, Frerich B, Gerber T. Bioactive coating on porous materials with an interconnected pore system to improve osseointegration. Key Eng Mater. 2012;493-494: 499-503.

45. Donath K, Breuner G. A method for the study of undecalcified bones and teeth with attached soft tissues. The Säge-Schliff (sawing and grinding) technique. J Oral Path. 1982;11:318-326.

46. US Department of Health and Human Services; Food and Drug Administration; Center for Devices and Radiological Health. Guidance for Industry on the Testing of Metallic Plasma Sprayed Coatings on Orthopedic Implants to Support Reconsideration of Postmarket Surveillance Requirements. Silver Spring (MD): US Department of Health and Human Services; Feb 2000.

47. Gerber T. The subcritical preparation of aerogels based on sodium water glass. J Solgel Sci Technol. 1998;13:323-328.

48. Knoblich B, Gerber T. Aggregation in $\mathrm{sio}_{2}$ sols from sodium silicate solutions. J Non Cryst Solids. 2001;283:109-113.

49. Knoblich B, Gerber T. The arrangement of fractal clusters dependent on the ph value in silica gels from sodium silicate solutions. J Non Cryst Solids. 2001;296:81-87.

50. Brinker CJ, Scherer GW. Sol-Gel Science: The Physics and Chemistry of Sol-Gel Processing. San Diego (CA): Academic Press Inc; 1990.

51. Gerber T, Holzhüter G, Götz W, Bienengräber V, Henkel KO, Rumpel E. Nanostructuring of biomaterials - a pathway to bone grafting substitute. Eur J Trauma. 2006;32(2):132-140.

52. Iler RK. The Chemistry of Silica: Solubility, Polymerization, Colloid and Surface Properties and Biochemistry of Silica. New York: John Wiley \& Sons, Inc; 1979.

53. Kortesuo P, Ahola M, Kangas M, et al. Alkyl-substituted silica gel as a carrier in the controlled release of dexmedetomidine. J Control Release. 2001;76(3):227-238.

54. Kortesuo P, Ahola M, Kangas M, et al. In vitro release of dexmedetomidine from silica xerogel monoliths: effect of sol-gel synthesis parameters. Int J Pharm. 2001;221(1-2):107-114.

55. Kortesuo P, Ahola M, Karlsson S, Kangasniemi I, Yli-Urpo A, Kiesvaara J. Silica xerogel as an implantable carrier for controlled drug delivery - evaluation of drug distribution and tissue effects after implantation. Biomaterials. 2000;21(2):193-198.

56. Luo Q, Andrade JD. Cooperative adsorption of proteins onto hydroxyapatite. J Colloid Interface Sci. 1998;200:104-113.

57. Yin G, Liu Z, Zhan J, Ding F, Yuan N. Impacts of the surface charge property on protein adsorption on hydroxyapatite. Chem Eng J. 2002;87: 181-186.

58. Rosengren A, Pavlovic E, Oscarsson S, Krajewski A, Ravaglioli A, Piancastelli A. Plasma protein adsorption pattern on characterized ceramic biomaterials. Biomaterials. 2002;23:1237-1247. 
59. Roberts WE, Turly PK, Brezniak N, Fielder PJ. Implants: bone physiology and metabolism. CDA J. 1987;15:54-61.
60. Götz W. [Osseointegration - Biological and clinical basics]. ZWR. 2010;119(11):550-558. German.

\section{Publish your work in this journal}

The International Journal of Nanomedicine is an international, peerreviewed journal focusing on the application of nanotechnology in diagnostics, therapeutics, and drug delivery systems throughout the biomedical field. This journal is indexed on PubMed Central, MedLine, CAS, SciSearch ${ }^{\circledR}$, Current Contents ${ }^{\circledR} /$ Clinical Medicine,
Journal Citation Reports/Science Edition, EMBase, Scopus and the Elsevier Bibliographic databases. The manuscript management system is completely online and includes a very quick and fair peer-review system, which is all easy to use. Visit http://www.dovepress.com/ testimonials.php to read real quotes from published authors. 